\title{
Médiévales
}

Langues, Textes, Histoire

49 | automne 2005

La paroisse, genèse d'une forme territoriale

\section{Karen A. Winstead (ed.), Chaste passions. Medieval English martyr legends}

Ithaca/Londres, Cornell University Press, 2000, 201 p., 7 ill.

\section{Chloé Maillet}

\section{OpenEdition}

\section{Journals}

Édition électronique

URL : https://journals.openedition.org/medievales/1217

DOI : 10.4000/medievales. 1217

ISSN : 1777-5892

\section{Éditeur}

Presses universitaires de Vincennes

Édition imprimée

Date de publication : 1 décembre 2005

Pagination : 182-185

ISBN : 2-84292-177-1

ISSN : 0751-2708

\section{Référence électronique}

Chloé Maillet, «Karen A. Winstead (ed.), Chaste passions. Medieval English martyr legends », Médiévales [En ligne], 49 | automne 2005, mis en ligne le 12 mars 2007, consulté le 24 avril 2022. URL : http:// journals.openedition.org/medievales/1217 ; DOI : https://doi.org/10.4000/medievales.1217

\section{Ce document a été généré automatiquement le 24 avril 2022.}

Tous droits réservés 


\title{
Karen A. Winstead (ed.), Chaste passions. Medieval English martyr legends \\ Ithaca/Londres, Cornell University Press, 2000, 201 p., 7 ill.
}

\author{
Chloé Maillet
}

1 Le livre de Karen Winstead est un recueil de vies de martyres traduites en anglais moderne, et il s'adresse à un public large, ceux qui, selon l'auteur, "ont grandi en entendant les histoires des saints ». Après avoir publié, en 1997, une étude sur les légendes de vierges martyres au bas Moyen Âge en Angleterre, l'auteur, par ailleurs professeur de littérature anglaise à l'Ohio State University, se vit suggérer par son éditeur une traduction en anglais moderne des sources qu'elle avait exploitées. Le livre dont il est question ici est le résultat de cette entreprise. On y trouvera un recueil de seize vies de vierges martyres de la basse Antiquité telles qu'elles furent rédigées en Angleterre en langue vernaculaire entre le début du treizième et la fin du quinzième siècle. Certains compilateurs et traducteurs sont anonymes, d'autres sont restés célèbres, mais ils évoquent presque tous leur ambition qui était de rendre accessible à un public illettré les vies et miracles des saintes martyres. Dans la continuité des auteurs médiévaux anglais, l'auteur tente de donner au lecteur contemporain un accès juste mais aisé à ces textes hagiographiques. D'ou le choix de ne proposer que de brèves (mais éclairantes) notices, de traduire les vers en prose, et de transposer fidèlement le langage parlé, de manière parfois quelque peu étonnante, sans hésiter, notamment, à rendre la crudité du langage du South English Legendary, dans lequel les martyres traitent à de multiples reprises leurs bourreaux de assholes.

2 Le recueil propose donc, dans un ordre chronologique, les vies des seize saintes Julienne, Agathe, Lucie, Barbe, Anastasie, Cécile, Christine, Eugénie, Winifred, Marguerite et Pétronille, Agnès et Dorothée, la longue vie anonyme de Catherine, et enfin celle d'Ursule et les onze mille vierges). Sont également publiés en annexe trois textes dont les éditions étaient rares ou inexistantes: les vies de Justine et Barbe extraites du South English Legendary, ainsi que la vie anonyme de sainte Catherine. 
Chacune de ces vies est précédée d'une notice introductive et d'une bibliographie. Une introduction de sept pages présente l'ensemble en reprenant une partie des conclusions de l'ouvrage précédent de l'auteur.

3 Le recueil s'ouvre avec une vie anonyme de sainte Julienne, écrite vers 1200, qui narre la vie de cette jeune fille refusant le mariage arrangé par son père Africanus (oppresseur des chrétiens) et repoussant les attaques du diable. Les quatre textes qui suivent sont extraits du South English Legendary, une anthologie volumineuse composée dans la deuxième moitié du treizième siècle, comprenant presque une centaine de récits, et dont on ne connaît pas moins de cinquante et un manuscrits. L'auteur a extrait de ce texte les vies de sainte Agathe, Lucie, Justine et Barbe. Ces vies ont la particularité, notamment en ce qui concerne les deux premières, de présenter les légendes dans un style très vif et cru, fourmillant de scènes d'action et de violence. Comme deux de ces vies n'avaient pas encore été éditées, l'auteur propose en annexe sa transcription de la vie de sainte Justine selon le manuscrit Egerton 1993 de la British Library, et de la vie de sainte Barbe telle qu'elle se trouve dans le Ms. Rawl Poet. 225 de la Bodleian Library d'Oxford. Ensuite, nous lisons la vie d'Anastasie, la sainte qui parvint à échapper aux affres conjugales grâce au décès miraculeux et libérateur de son époux. Cette vie est tirée du recueil connu sous le nom de North English Legendary, rédigé à la fin du quatorzième siècle. Cette compilation, dédiée également à un public large, abonde particulièrement en épisodes narratifs assez humoristiques qui scandent le récit des exploits des saints. Vient ensuite la traduction de ce qui reste sans doute la plus célèbre des légendes de saints écrites en Angleterre, la vie de sainte Cécile traduite par Geoffrey Chaucer d'après la Légende Dorée. Si l'on rencontre ce texte dans le récit de la deuxième nonne des Contes de Canterbury, Chaucer l'avait pourtant écrit dans les années 1370 ou au début des années 1380, au moins une décennie avant d'entamer les Contes. On considère généralement que c'est à partir de ce texte que la légende hagiographique devient réellement un genre littéraire. Suit la seconde légende connue en Angleterre écrite par des laïcs, la vie de sainte Christine par Guillaume Paris. Elle fut rédigée alors qu'il était prisonnier politique en 1397. La vie d'Eugénie issue du Légendier écossais nous fait entrer dans le monde des saintes travesties en homme, un type de récit qui connut de multiples avatars tout au long du Moyen Âge. Les auteurs de ce recueil, rédigé vers la fin du quatorzième siècle ou le tout début du quinzième siècle, sont restés anonymes. La vie de sainte Winifred, écrite par le prolifique John Mirk à la fin du quatorzième siècle, nous présente une héroïne moins agressive, et qui est sans doute la seule vierge à avoir survécu à une décapitation. Les vies de Marguerite et Pétronille écrites par John Lydgate apportent une nouveauté dans le genre, ce que $K$. Winstead considère donc comme étant une approche véritablement littéraire du genre. La vie de saint devient avec lui véritablement une œuvre poétique riche en métaphores et en descriptions, à la versification recherchée. Osbern Bokenham, contemporain de Lydgate, écrivit également entre 1430 et 1440 des vies de saintes inspirées par la Légende Dorée, dont sont traduites ici les vies d'Agnès et Dorothée. $\mathrm{K}$. Winstead traduit également une des deux versions détaillées de la vie de sainte Catherine, qui épousa le Christ en une cérémonie de noces mystiques, qui fut sans doute rédigée dans les années 1420 . C'est ce texte qui expose en détail la vie de cette sainte très populaire qui fut souvent préférée à celle, plus succincte, de Jacques de Voragine, et qui fut incorporée au légendier de Caxton. Ce texte n'étant disponible que dans une édition rare est également édité en version originale en annexe. Le recueil se 
clôt avec la vie de sainte Ursule et ses onze mille compagnes, rédigée par un auteur anonyme autour de 1485 .

4 K. Winstead introduit ces vies de saints en expliquant, peut-être un peu rapidement, qu'écrites souvent longtemps après la mort de leurs protagonistes, et présentant souvent la répétition des mêmes topoi, elles en deviennent "anhistoriques ». Elle s'appuie pour cela sur les travaux quelque peu vieillis d'Hippolyte Delahaye. Elle évoque également la récupération polysémique des vies de vierges par les féministes, d'aucuns y voyant une image particulièrement négative du féminin (à travers une valorisation extrême de la chasteté et de la mort adolescente), alors que d'autres ont tendance à lire positivement une image combative des vierges en tant que rebelles affrontant avec courage la "patriarchie » oppressante. La traduction de ces vies en langue vernaculaire à partir du treizième siècle s'est faite en réponse à une recherche de piété active de la part des laïcs. Il est d'ailleurs intéressant de noter combien les vies rédigées à cette époque peuvent prendre des distances par rapport aux vies latines originales, de façon à s'adapter aux intérêts du siècle et aux attentes des lecteurs. Pour tracer un schème général, l'auteur indique qu'au quatorzième siècle, les légendes se focalisent sur le conflit et accentuent le comportement antisocial des saintes, alors qu'au quinzième siècle, la tendance est moins portée à insister sur la confrontation, mais davantage sur la prière et la dévotion, portraiturant ainsi des héroïnes plus acceptables socialement, et mieux à même de devenir des modèles de comportement.

On aurait pu préférer à ce recueil une édition bilingue qui aurait permis de mieux appréhender cet échantillon de textes. Mais on ne peut que se réjouir que des initiatives de ce type voient le jour et permettent à un public profane de lire ces versions des vies de saints, souvent bien différentes de celle de la Légende dorée et d'autres recueils amplement diffusés. L'introduction et les synthétiques notices agrémentent cette lecture qui incite à contrecarrer à nouveau l'idée, encore trop répandue, que les vies de vierges martyres ne sont que d'ennuyeux récits stéréotypés. 